\title{
Effects of Beta-Adrenergic Blockers with Different Ancillary Properties on Lipid Peroxidation in Hyperthyroid Rat Cardiac Muscle*
}

\author{
Kohtaro ASAYAMA, Kazushige DOBASHi, Hidemasa HAYASHibE \\ AND KIYOHIKO KATO
}

Department of Pediatrics, Yamanashi Medical College, Yamanashi 409-38, Japan

\begin{abstract}
To determine whether beta-blockade protects rat heart against thyroxine $\left(\mathrm{T}_{4}\right)$-induced accelelation of lipid peroxidation, in vivo effects of 3 beta-blockers with different ancillary properties on the mitochondrial oxidative enzyme, antioxidant enzymes and lipid peroxide were investigated. The rats were rendered hyperthyroid by adding $\mathrm{T}_{4}$ to their drinking water for 3 weeks and were treated simultaneously with either carteolol (a blocker with partial agonist activity; $30 \mathrm{mg} / \mathrm{kg} /$ day), atenolol $(50 \mathrm{mg} / \mathrm{kg} /$ day) or arotinolol (a blocker with weak alpa-blocking action; $50 \mathrm{mg} / \mathrm{kg} / \mathrm{day})$. The $\mathrm{T}_{4}$-induced tachycardia was alleviated completely by either atenolol or arotinolol, but only partially by carteolol. Cytochrome c oxidase activity in the heart muscle was increased by $\mathrm{T}_{4}$ with a parallel increase in manganese (mitochondrial) superoxide dismutase. Atenolol, but neither carteolol nor arotinolol, suppressed this increase. Similarly, the $\mathrm{T}_{4}$-induced acceleration of lipid peroxidation was suppressed by atenolol alone. Glutathione peroxidase was markedly decreased, and both copper zinc (cytosolic) superoxide dismutase and catalase were also decreased or tended to be decreased by $\mathrm{T}_{4}$. The levels of these 3 enzymes were only minimally affected by the beta-blocker treatments. These results suggest that beta-blockade suppresses mitochondrial hypermetabolism and protects heart muscle against oxidative stress in hyperthyroidism, and that the ancillary properties of beta-blockers such as partial agonist activity and alpha-blocking action negate the protection.
\end{abstract}

\section{Received April 28, 1989}

Address all correspondence and reprint requests to : Kohtaro ASAYAMA, M.D., Department of Pediatrics, Yamanashi Medical College, 1110 Shimokato, Tamahocho, Nakakomagun, Yamanashi Pref. 409-38, Japan

* The authors sincerely thank Teiko Niitsu and Hajime Obi for their technical assistance. This work was supported in part by Grants-in-Aid 62770644 and 6370431 from the Ministry of Education (Japan).
Accelerated mitochondrial respiratory electron transport has been postulated to result in increased production of superoxide anion radical (Boveris et al., 1976). This species can be an initiator of free radical chain reaction, eventually leading to peroxidation of mitochondrial membrane lipid unless removed by a coordinate action of superoxide dismutases (SODs) and scavenger enzymes of hydrogen peroxide (i. e., gluta- 
thione peoxidase, GPX, and catalase, CAT). We previously demonstrated that exogeneously administered $\mathrm{T}_{4}$ accelerated mitochondrial oxidative metabolism in rat heart, resulting in an increase in lipid peroxide (thiobarbituric acid-reactive substances, TBARS) despite the reactive increase in mitochondrial (manganese) SOD (MnSOD) (Asayama et al., 1987).

Hyperthyroidism is known to be associated with an increase in heart rate, cardiac work, and myocardial contractility, and also with cardiac hypertrophy in experimental animals (Morkin et al., 1983). Thyroid hormone has been shown to potentiate a beta-adrenergic effect by increasing the number of beta-adrenoceptors in the heart (Tse et al., 1980). Accordingly, beta-blockers alleviate certain cardiac manifestations such as tachycardia, and an increase in cardiac output and cardiac work rapidly and independently of the thyroid hormone status (Klein and Levey, 1984), and they are at least of some benefit in the management of hyperthyroidism. Currently, beta-blockers with different ancillary properties are available. All beta-blockers have the property of blocking beta $_{1}$ receptors but differ from one another in other respects such as selectivity for two subgroups of beta-adrenoceptor, partial agonist activity (PAA), and alphablockade. All such ancillary properties are generally considered to afford safety by reducing untoward effects secondary to nonselective beta-blockade (Man In'T Veld, 1987). However, it has not been determined whether such properties are beneficial or not in hyperthyroid heart in which the tissue is hypersensitive to catecholamine (Tse et al., 1980).

The presents study evaluated the effects of 3 different beta-blockers. Carteolol (Otsuka Pharmaceutical Co., Tokushima, Japan) (Yabuuchi and Kinoshita, 1974) and arotinolol (Sumitomo Pharmaceuticals Co., Tokyo, Japan) (Hara et al., 1978) are nonbeta $_{1}$-selective blockers; the former possesses
PAA, and the latter an alpha-blocking action and no PAA. Atenolol (ICI Pharma Co., Tokyo, Japan) (Barrett et al., 1973) is

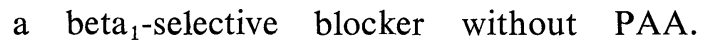
Each drug acts longer than propranolol, and does not need frequent administration or continuous infusion to maintain the effect. Neither drug possesses membrane stabilizing activity which is known to affect the conversion of $T_{4}$ to $T_{3}$ in the peripheral circulation.

The effect of beta-blockers on the $T_{4^{-}}$ induced oxidative stress in heart muscle has not been studied previously. In the present study, the in vivo effects of long-term administration of the three beta-blockers on the levels of mitochondrial oxidative enzyme (cytochrome c oxidase), antioxidant enzymes and TBARS in hyperthyroid rat heart muscle were investigated.

\section{Materials and Methods}

Five-week-old male Sprague-Dawley rats (Shizuoka Laboratory Animal Center, Shizuoka. Japan) were fed a standard chow. The euthyroid control groups were given tap water. The remaining rats $\left(\mathrm{T}_{4}\right.$ and $\mathrm{T}_{4}+$ beta-blocker groups) were rendered hyperthyroid by the administration of $12 \mathrm{mg} / 1$ of L-thyroxin in their drinking water over a 3-week period, as described previously (Asayama et al., 1987). Two sets of experiments (Exp) were performed. Each group for both Exp consisted of 7 animals. In Exp I, one group each of rats was treated with either carteolo1 $(30 \mathrm{mg} / \mathrm{kg} / \mathrm{day})$ or atenolol $(50 \mathrm{mg} / \mathrm{kg} /$ day), injected sc every $12 \mathrm{~h}$ (at $0900 \mathrm{~h}$ and $2100 \mathrm{~h}$ ). The control and $T_{4}$ groups were injected with saline. In Exp II, one group was given arotinolol $(50 \mathrm{mg} / \mathrm{kg} /$ day po), every $24 \mathrm{~h}$, at $0900 \mathrm{~h}$. The control and $\mathrm{T}_{4}$ groups were given the vehicle $(0.5 \%$ methyl cellulose). The beta-blocker treatments were started stimultaneously with $\mathrm{T}_{4}$. Heart rates were measured in conscious animals heated at $38^{\circ} \mathrm{C}$ for $10 \mathrm{~min}$ by the tail cuff plethysmographic method with a pneumatic tail pulse transducer UR-1000 (Ueda Electronic works Co., Tokyo Japan). The rats were killed under pentobarbital 
anesthesia $(50 \mathrm{mg} / \mathrm{kg} \mathrm{ip}$ ), and their sera and heart muscles were obtained.

Serum levels of $T_{3}$ and $T_{4}$ in the rats given $\mathrm{T}_{4}$ were well in the hyperthyroid range and were similar to those values reported previously (Asayama et al., 1987). The beta-blockers did not affect the serum thyroid hormone levels (data not shown). The tissue homogenate was prepared as described previously (Asayama et al., 1987). The rat MnSOD and cytosolic (copper zinc) SOD (CuZnSOD) were assayed by specific radioimmunoassays (Asayama and Burr, 1985). Cytochrome c oxidase, glutathione peroxidase and catalase were assayed spectrophotometrically, and TBARS fluorimetrically, also as described previously (Asayama et al., 1987). Protein was measured by the technique of Lowry et al., (1951).

The data are presented as the mean \pm SE. Statistical significance was determined by the method of least significant difference, calculated after one-way analysis of variance.

\section{Results}

\section{Heart rate and heart weight relative to body weight}

Table 1 lists the heart rates measured one day before sacrifice for each group of animals, the heart weights and the heart weights relative to body weight at sacrifice. The heart rates in the $T_{4}$ groups in Exp I and II increased to a similar extent. Carteolol partially alleviated the tachycardia. The heart rate was suppressed less effectively at $3 \mathrm{~h}$ than at $12 \mathrm{~h}$ after the administration of carteolol. On the other hand, both atenolol in Exp I and arotinolol in Exp II suppressed the tachycardia completely not only at $3 \mathrm{~h}$ but also at $12 \mathrm{~h}$ (for atenolol) and $24 \mathrm{~h}$ (for arotinolol) after the drug administration. The heart was markedly hypertrophied in all $T_{4}$-treated groups in both Exp I and II, when judged by either heart weight or heart weight relative to body weight. Neither carteolol nor atenolol, but arotinolol slightly alleviated the hypertrophy.

\section{Cytochrome c oxidase, antioxidant} enzymes and TBARS in heart

Cytochrome $\mathrm{c}$ oxidase activity in heart muscle was increased in the $\mathrm{T}_{4}$ groups in Exp I and II, and atenolol in Exp I

Table 1. Heart rates, heart weight relative to body weight

\begin{tabular}{llcc}
\hline \hline & $\begin{array}{c}\text { Heart rates } \\
\text { (beats/min) }\end{array}$ & $\begin{array}{c}\text { Heart wt } \\
(\mathrm{mg})\end{array}$ & $\begin{array}{c}\text { Heart wt/body/wt } \\
(\mathrm{mg} / \mathrm{g})\end{array}$ \\
\hline Experiment I & $398 \pm 8$ & $0.96 \pm 0.03$ & $3.15 \pm 0.07$ \\
Controls & $494 \pm 10^{\mathrm{b}}$ & $1.28 \pm 0.02^{\mathrm{b}}$ & $4.96 \pm 0.05^{\mathrm{b}}$ \\
$\mathrm{T}_{4}$ & $457 \pm 12^{\mathrm{b}, \mathrm{d}}$ & $1.24 \pm 0.02^{\mathrm{b}}$ & $4.90 \pm 0.11^{\mathrm{b}}$ \\
$\mathrm{T}_{4}+$ carteolo1 3 h & $431 \pm 5^{\mathrm{a}, \mathrm{e}, \mathrm{f}}$ & - & - \\
$(30 \mathrm{mg} / \mathrm{kg} /$ day) 12 h & $400 \pm 7^{\mathrm{e}}$ & $1.26 \pm 0.04^{\mathrm{b}}$ & $4.78 \pm 0.07^{\mathrm{b}}$ \\
$\mathrm{T}_{4}+$ atenolo1 3 h & $414 \pm 7^{\mathrm{e}}$ & - & \\
(50 mg/kg/day) 12 h & & & \\
Experiment II & $399 \pm$ & $0.74 \pm 0.01$ & $2.64 \pm 0.04$ \\
Controls & $492 \pm 12^{\mathrm{b}}$ & $1.21 \pm 0.04^{\mathrm{b}}$ & $4.38 \pm 0.15^{\mathrm{b}}$ \\
$\mathrm{T}_{4}$ & $393 \pm 7^{\mathrm{e}}$ & $1.10 \pm 0.03^{\mathrm{b}, \mathrm{c}}$ & $4.06 \pm 0.07^{\mathrm{b}, \mathrm{c}}$ \\
$\mathrm{T}_{4}+$ arotinolol 3 h & $395 \pm 7^{\mathrm{e}}$ & - & \\
\hline
\end{tabular}

Heart rates were measured one day before sacrifice. Data are means \pm SE of 7 observations. For the groups treated with beta-blockers, the heart rates were measured at the indicated intervals after the last dose of the drugs. The heart weights and relative heart weights were the values at sacrifice.

Statistical significance: a. p<0.01, b. p $<0.001$ (vs. controls), c. p<0.05, d. p<0.01, e. $\mathrm{p}<0.001$ (vs. $\mathrm{T}_{4}$ ), and f. $\mathrm{p}<0.05$ (vs. $3 \mathrm{~h}$ ). 
normalized the activity (Fig 1). Neither carteolo1 (Exp I) nor artinolol (Exp II) af-

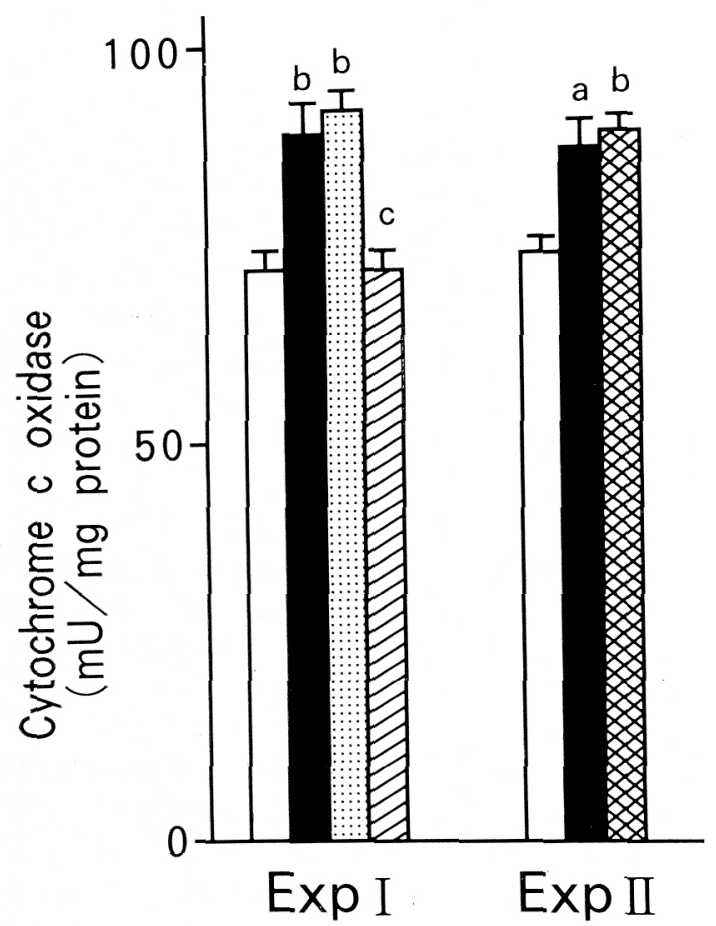

Fig. 1. Cytochrome c oxidase activity in heart muscle. Data are means $\pm \operatorname{SE}($ no. $=7) . \quad \square$ :

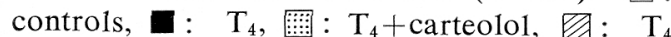
+ atenolol, and $\mathrm{T}_{4}+$ arotinolol groups. Statistical significance: a. $\mathrm{p}<0.01$, b. $\mathrm{p}<$ 0.001 (vs. controls), and c. $\mathrm{p}<0.001$ (vs. $\mathrm{T}_{4}$ ). fected the increase. Similarly, the MnSOD levels in the $T_{4}$ groups in Exp I and II were increased, and only atenolol, but neither carteolol nor arotinolol, restored

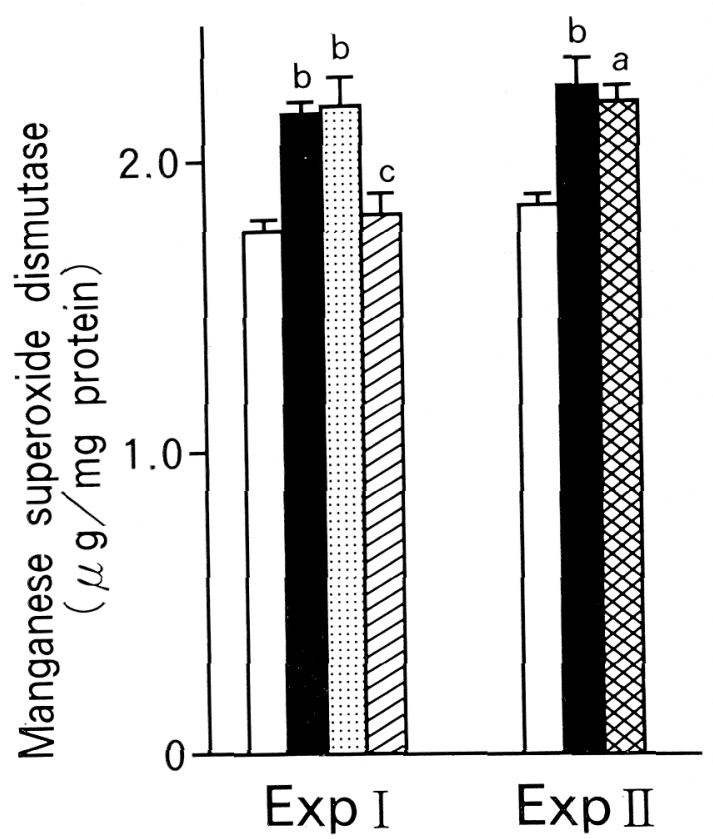

Fig. 2. Concentration of manganese superoxide dismutase in heart muscle. Data are means \pm SE (no.=7). Each bar represents the group indicated in the legend to Fig. 1. Statistical significance: a. $p<0.01$, b. $p<0.001$ (vs. controls), and c. $\mathrm{p}<0.001$ (vs. $\mathrm{T}_{4}$ ).

Table 2. Copper zinc superoxide dismutase, glutathione peroxidase and catalase in heart muscle

\begin{tabular}{lccc}
\hline & CuZn-superoxide dismutase & Glutathione peroxidase & Catalase \\
\hline Experiment I & & & \\
Controls & $1.22 \pm 0.05$ & $625 \pm 19$ & $9.60 \pm 0.44$ \\
$\mathrm{~T}_{4}$ & $1.09 \pm 0.03^{\mathrm{b}}$ & $377 \pm 10^{\mathrm{b}}$ & $8.53 \pm 0.41$ \\
$\mathrm{~T}_{4}+$ carteolo1 & $1.09 \pm 0.03^{\mathrm{a}}$ & $484 \pm 14^{\mathrm{b}, \mathrm{e}}$ & $8.50 \pm 0.51$ \\
$\mathrm{~T}_{4}+$ atenolol & $0.99 \pm 0.03^{\mathrm{b}, \mathrm{c}}$ & $365 \pm 15^{\mathrm{b}}$ & $7.07 \pm 0.42^{\mathrm{b}, \mathrm{c}}$ \\
Experiment II & & & \\
Controls & $1.33 \pm 0.03$ & $591 \pm 14$ & $12.49 \pm 0.36$ \\
$\mathrm{~T}_{4}$ & $1.14 \pm 0.02^{\mathrm{b}}$ & $367 \pm 8^{\mathrm{b}}$ & $8.49 \pm 0.53^{\mathrm{b}}$ \\
$\mathrm{T}_{4}$ +arotinolo1 & $1.12 \pm 0.04^{\mathrm{b}}$ & $340 \pm 6^{\mathrm{b}}$ & $6.06 \pm 0.45^{\mathrm{b}, \mathrm{d}}$ \\
\hline
\end{tabular}

Data are means \pm SE of 7 observations. Value are expressed as $\mu \mathrm{g} / \mathrm{mg}$ protein for CuZnsuperoxide dismutase, $\mathrm{mU} / \mathrm{mg}$ protein for glutathione peroxidase activity, and Unit $\mathrm{K}\left(\mathrm{s}^{-1}\right) / \mathrm{g}$ protein for catalase activity. Statistical significance: a. $p<0.02$, b. $p<0.001$ (vs. controls), and c. $\mathrm{p}<0.05$, d. $\mathrm{p}<0.01$, e. $\mathrm{p}<0.001$ (vs. $\mathrm{T}_{4}$ ). 


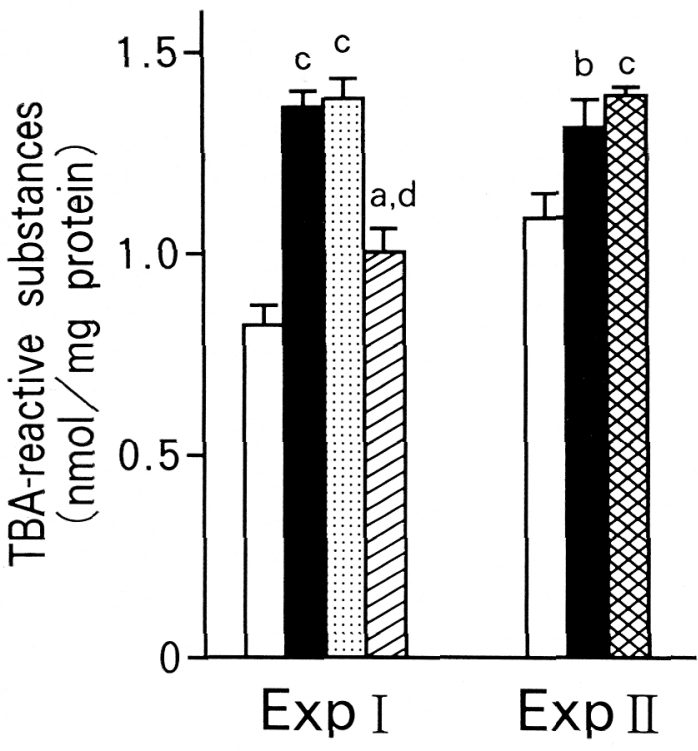

Fig. 3. Level of thiobarbituric acid-reactive substances in heart muscle. Data are means $\pm \mathrm{SE}($ no. $=7)$. Each bar represents the group indicated in the legend to Fig. 1. Statistical significance: a. $\mathrm{p}<0.02$, b. $\mathrm{p}<0.01$, c. $\mathrm{p}<$ 0.001 (vs. controls), and d. $\mathrm{p}<0.001$ (vs. $\mathrm{T}_{4}$ ).

the increase to the control level (Fig. 2). Table 2 lists the levels of CuZnSOD, GPX and CAT in the heart muscle. CuZnSOD was decreased in all $\mathrm{T}_{4}$-treated groups in Exp I and II. Similarly, GPX activity was decreased markedly in all- $\mathrm{T}_{4}$-treated groups, whereas it was slightly restored toward normal in the carteolol group. CAT was also decreased or tended to be decreased by $\mathrm{T}_{4}$, and was further decreased by either atenolol or arotinolol treatment. The TBARS levels in the $T_{4}$ groups in Exp I and II were increased, and similarly to cytochrome c oxidase and MnSOD, atenolol, but neither carteolol nor arotinolol, significantly suppressed increase (Fig. 3). The value in the atenolol group was slightly higher than that in the control group in Exp I.

\section{Discussion}

The tachycardia was suppressed completely by atenolol and arotinolol, whereas only the former normalized the oxidative enzyme, MnSOD and lipid peroxidation. On the other hand, the cardiac hypertrophy was only slightly alleviated by arotinolol alone. Carteolol alleviated the tachycardia only partially and affected neither the oxidative metabolism, lipid peroxidation nor heart size. All beta-blockers used here possess a beta ${ }_{1}$ blocking properties. Thus, the differential effects observed here appear to be due the differences in their ancillary properties. In the preliminary experiment, atenolol affected neither the oxidative enzyme nor the antixoidant enzymes in euthyroid animals, and therefore the metabolic suppression by atenolol observed here does not appear to be a nonspecific effect (data not shown).

The dosage of carteolol used here is 3 times as large as that reported to be maximally effective on the cardiac hypertrophy in spontaneously hypertensive rats (Igawa et al., 1984). The beta-blockers possessing PAA have been reported to reduce the heart rate to a lesser extent than those without PAA in clinical hyperthyroidism (Murchison et al., 1976). In the present study, carteolol suppressed the tachycardia less effectively at $3 \mathrm{~h}$ than at $12 \mathrm{~h}$ after the administration, although the tissue concentration should be higher at $3 \mathrm{~h}$ than at $12 \mathrm{~h}$. This may imply that hypersensitivity to catecholamine in hyperthyroid heart exaggerates the stimulative property of carteolol.

Whether the cardiac hypertrophy is a direct effect of thyroid hormone or an adaptive response to the increased cardiac work is still in debate. According to one recent report (Klein, 1988), $10 \mathrm{mg} /$ animal/ day of propranolol completely prevented not only tachycardia but also cardiac hyper- 
trophy in $T_{4}$-treated rats. It has also been reported that hypertrophy does not occur in a heterotopically transplanted, nonworking heart in hyperthyroid rat (Klein and Hong, 1986). These findings support the view that the hypertrophy is secondary to the work overload. In contrast to this, other investigators (Gerdes et al., 1987; Limas and Limas, 1987) did not find a significant inhibition of the thyroid hormone induced cardiac hypertrophy by beta-blocker treatment despite the suppression of tachycardia. In the present study, atenolol administered at a comparable dose to that of propranolol used in the aforementioned study completely normalized the heart rate and oxidative enzyme, but did not affect the heart size. Thus, the hypertrophy is, at least in part, mediated by a nonmechanical factor.

The induction of SOD is considered to afford protection against oxidant challenge (Freeman and Crapo, 1981) and this notion is supported by the reported effectiveness of exogenously administered SOD for protection aginst oxidative injury (Burton, 1985). However, an increase in SOD without a concurrent increase in other antioxidant enzymes has recently been reported to make the organ more susceptible to oxidant toxicity (Scott et al., 1987). In the hyperthyroid heart, MnSOD was increased presumably as an adaptive response to enhanced oxidative stress, whereas the other antioxidant enzymes (especially GPX) were decreased. Such an imbalanced induction of the MnSOD did not appear to afford protection. Therefore, the normalization of lipid peroxide observed in the atenolol group appeared to be primarily due to the suppression of the oxidative metabolism.

A beta-adrenergic mechanism is known to play an essential role in modulating the oxidative metabolism in heart muscle. Beta ${ }_{1}$ blockade suppresses myocardial oxygen consumption by reducing heart rate, myocardial contractility and coronary blood flow (Taylor, 1987). Additionally, the re- duction in systemic blood pressure reduces the pressure work of the left ventricle, and contributes to the suppression of excess oxygen consumption. On the other hand, the cardiac beta-blocade is also known to induce reflex vasoconstriction mediated by an alpha-adrenergic effect. The properties of PAA and ancillary alpha-blockade prevent this response, and this is generally considered to make the use of beta-blockers safer in most situations (Man In'T Veld, 1987). However, the present study disclosed that the restoration of the oxidative metabolism and also presumably the coronary blood flow by such ancillary properties resulted in the failure to suppress the accleration of lipid peroxidation in the hyperthyroid heart muscle.

Thyrotoxic cardiomyopathy is not yet a well defined disease entity. However, a reversible and functional myocardial dysfunction is known to exist in clinical hyperthyroidism (Forfar et al., 1982). Furthermore, hyperthyroidism is reported to induce ultrastructural changes in heart mitochondria in experimental animals (Callas and Hayes, 1974). It has been demonstrated that active oxygen species can mediate myocardial damage (Jackson et al., 1986), and that exogenously administered SOD partially protects against oxidative heart injury (Burton, 1985). The pathophysiological implication of the thyroid hormone induced increase in the myocardial lipid peroxide level and the suppression of that due to atenolol treatment observed here still need to be clarified further. The acceleration of lipid peroxidation can be an early biochemical change predisposing to cardiac dysfunction in hyperthyroidism, and the inhibition of such a process is potentially important. The present results suggest

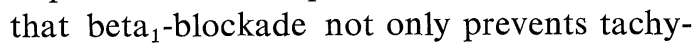
cardia but also protects the myocardium against oxidative stress induced by hyperthyroidism, and that the ancillary properties of beta-blockers such as PAA and alpha- 
blockade negate the protection. Such differential effects of the beta-blockers on the lipid peroxidation are considered to be brought about by the altered sensitivity of the hyperthyroid heart to catecholamine.

\section{References}

Asayama, K. and I. M. Burr (1985). Rat superoxide dismutases: Purification, labeling, immunoassay, and tissue concentration. $J$. Biol. Chem. 260, 2212-2217.

Asayama, K., K. Dobashi, H. Hayashibe, Y. Megata and K. Kato (1987). Lipid peroxidation and free radical scavengers in thyroid dysfunction in the rat. Endocrinology 121, 2112-2118.

Barrett, A. M., J. Carter, J. D. Fitzgerald, R. Hull and D. Le Count (1973). A new type of cardioselective adrenoceptive blocking drugs. Br. J. Pharmacol. 48, 340. (Abstract).

Boveris, A., E. Cadenas and A. O. M. Shoppani (1976). Role of ubiquinone in the mitochondrial generatian of hydrogen peroxide. Biochem. J. 156, 435-444.

Burton, K. P. (1985). Superoxide dismutase enhances recovery following myocardial ischemia. Am. J. Physiol. 248 H637-H643.

Callas, G. and J. R. Hayes (1974). Alteration in fine structure of cardiac muscle mitochondria induced by hyperthyroidism. Anat. Rec. 178, 539-550.

Forfar, J. C., A. L. Muir, S. A. Sawers and A. D. Toft (1982). Abnormal left ventricular function in hyperthyroidism. $N$. Engl. J. Med. 307, 1165-1170.

Freeman, B. A. and J. D. Crapo (1981). Hyperoxia increases oxygen radical production in rat lungs and lung mitochondria. J. Biol. Chem. 256, 10986-10991.

Gerdes, A. M., J. A. Moore and J. M. Hines (1987). Regional changes in myocyte size and number in propranolol-treated hyperthyroid rats. Lab. Invest. 57, 708-713.

Hara, Y., E. Sato, A. Miyagishi, A. Aisaka and T. Hibino (1978). Synthesis and betaadrenergic blocking action of a new thiazolylthiopropanolamine derivative. J. Pharmaceut. Sci. 67, 1334-1335.

Igawa, G., K. Ikezono, K. Watanabe and Y. Kimura (1984). Dose-related inhibitory effects of the beta-adrenoceptor blocking drugs carteolol and propranolol on cardiac hypertrophy in spontaneously hypertensive rats. Eur. $J$. Pharmacol. 104, 93-99.

Jackson, C. V., J. K. Mickelson, T. K. Pope, P. S. Rao and B. R. Lucchesi (1986). $\mathrm{O}_{2}$ free radical-mediated myocardial and vascular dysfunction. Am. J. Physiol. 251, H1225H1231.

Klein, I. and G. S. Levey (1984). New perspectives on thyroid hormone, catecholamines, and the heart. Am. J. Med. 76, 167-172.

Klein I. and, C. Hong (1986). Effects of thyroid hormone on cardiac size and myosin content of the herotopically transplanted rat heart. J.Clin. Invest. 77, 1694-1698.

Klein, I. (1988). Thyroxine-induced cardiac hypertrophy: Time course of development and inhibition by propranolo1. Endocrinology 123, 203-210.

Limas, C. and C. J. Limas (1987). Influence of thyroid status on intracellular distribution of cardiac adrenoceptors. Circ. Res. 61, 824828.

Lowry, O. H., N. J. Rosenbrough, A. L. Farr and R. J. Randall (1951). Protein measurement with the Folin phenol reagent. J. Biol. Chem. 193, 265-275.

Man In'T Veld, A. J. (1987). Effect of beta blockers on vascular resistance in systemic hypertension. Am. J. Cardiol. 59, 21F-25F.

Morkin, E., I. L. Flink and S. Goldman (1983). Biochemical and physiologic effects of thyroid hormone on cardiac performance. Proq. Cardiovasc. Dis. 25, 435-464.

Murchison, L. E., P. D. Bewsher, M. I. Chesters and W. R. Ferrier (1976). Comparison of propranol and practolol in the management of hyperthyroidism. Br. J. Clin. Pharmacol. 3, 273-277.

Scott, M. D., S. R. Meshnick and J. W. Eaton (1987). Superoxide disumutase-rich bacteria. J. Biol. Chem. 262, 3640-3645.

Taylor, S. H. (1987). Role of cardioselectivity and intrinsic sympathomimetic activity in beta-blocking drug in cardiovascular disease. Am. J. Cardiol. 59, 18F-20F.

Tse, J., R. W. Wrenn and J. F. Kuo (1980). Thyroxin-induced changes in characteristics and activities of beta-adrenergic receptors and adenosine $3^{\prime}, 5^{\prime}$-monophosphate systems in the heart may be related to reputed catecholamine supersensitivity in hyperthyroidism. Endo- 
crinology 10, 6-15.

Yabuuchi, Y. and D. Kinoshita (1974). Cardiovascular studies of 5-(3-tert-butylamino-2hydroxy) propoxy-3, 4-dihydrocarbostyril hy- drochloride (OPC-1085), a new potent betaadrenergic agent. Jap. J. Pharmacol. 24, 853857. 